\title{
The importance of dissolved ferric iron in hydrothermal fluids
}

\author{
CHRISTOPHER H. GAMMONS ${ }^{1}$
}

${ }^{1}$ Montana Technological Univ., Butte, MT, 59701, USA

(cgammons@mtech.edu)

Dissolved ferric iron has traditionally been overlooked as a possible reactant in hydrothermal systems. This is surprising, considering the key role that ferric iron plays in low temperature geochemistry through the oxidation of pyrite and creation of acid rock drainage. Part of the problem is a lack of data on the stability and stoichiometry of aqueous $\mathrm{Fe}(\mathrm{III})$ species at high temperature. However, recent experiments by the author's group at Montana Tech have shown that 10 's to 1000 's of $\mathrm{mg} / \mathrm{L}$ of $\mathrm{Fe}$ (III) can be dissolved in the stability field of hematite as the $1: 4 \mathrm{FeCl}_{4}{ }^{-}$species at temperature $>250^{\circ} \mathrm{C}, \Sigma \mathrm{Cl}>3$ molal, and a $\mathrm{pH}$ range that is 1 2 units acidic of neutral. The dissolution of hematite under these conditions is independent of redox, and can be written as follows:

$0.5 \mathrm{Fe}_{2} \mathrm{O}_{3}+4 \mathrm{Cl}^{-}+3 \mathrm{H}^{+}=\mathrm{FeCl}_{4}^{-}+1.5 \mathrm{H}_{2} \mathrm{O}$

If hematite is present in an aquifer (e.g., a "red-bed"

sandstone) in contact with a hot, somewhat acidic brine, it will dissolve as $\mathrm{FeCl}_{4}{ }^{-}$unless there are other competing redox reactions involved.

Once formed, there are at least two ways that $\mathrm{FeCl}_{4}$ could influence water-rock interactions in hydrothermal systems. First, $\mathrm{FeCl}_{4}^{-}$is a powerful oxidant capable of breaking down sulfide minerals and releasing their contained metals into aqueous solution. In fact, dissolved ferric iron may be the only powerful oxidant in most deep, rock-buffered geothermal systems where atmospheric $\mathrm{O}_{2}$ has long ago reacted out. Second, high concentrations of dissolved ferric iron may precipitate directly as hypogene hematite, a common and sometimes dominant gangue mineral in porphyry-skarn and iron-oxide copper gold (IOCG) deposits. Conventional ideas on the genesis of hematite-cemented breccias in IOCG deposits usually involve oxidation of dissolved ferrous iron by $\mathrm{O}_{2}$. However, this mechanism requires a large supply of $\mathrm{O}_{2}$, something that is unlikely in most hydrothermal environments, especially considering the minimal solubility of dissolved oxygen in hot water. Instead, it is much easier to imagine large quantities of hematite precipitating directly by the reverse of reaction 1, e.g., by a simple drop in temperature, increase in $\mathrm{pH}$, or decrease in salinity (dilution). Because of the strong temperature dependence of reaction 1, $\mathrm{FeCl}_{4}{ }^{-}$could also be an important aqueous species in magmatic-hydrothermal fluids, even at near-neutral $\mathrm{pH}$, provided the magmas are oxidized $\left(\mathrm{SO}_{4}{ }^{2-}\right.$ stable). 